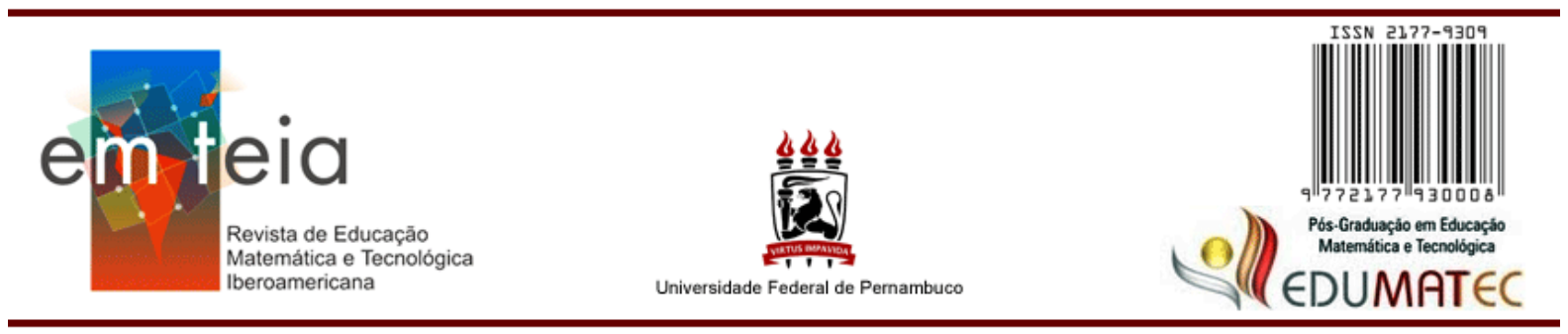

\title{
ISTO NÃO É MATEMÁTICA
}

\section{THIS IS NOT MATHEMATICS}

\author{
Virgínia Crivellaro Sanchotene \\ Doutoranda em Educação \\ UFRGS - RS - Brasil \\ vicrivellaro@hotmail.com \\ Cecília Bobsin do Canto \\ Mestranda em Educação \\ UFRGS - RS - Brasil \\ ceciliabobsin@gmail.com
}

\section{Resumo}

Este ensaio tem por objetivo questionar condutas baseadas em binarismos e automatismos, fortemente arraigadas no fazer do docente de matemática. Propõe-se uma discussão acerca do dizer "Isto não é matemática", enunciado repetido por nossos alunos ao se depararem com atividades que envolvam escrita, leitura, argumentação ou outros saberes que se distanciem de cálculos e fórmulas. Ao articular esta frase ao conceito de regimes de verdade, desenvolvido por Foucault, problematizamos vinculações a verdades estreitas que naturalizam práticas hierarquizantes na produção de modos de ser/estar/sentir-se professor de matemática, assinalando a importância de um exercício de liberdade e alteridade em nossas práticas cotidianas na sala de aula.

Palavras-Chave: docência. Professor de matemática. Liberdade. Regimes de verdade. Foucault.

\begin{abstract}
This essay aims to question conducts based on binarisms and automatisms, deeply rooted in the mathematics teacher's practice. We propose a discussion about the statement "This is not mathematics", a statement repeated by our students when they encounter activities involving writing, reading, argumentation or other knowledge that are distant from calculations and formulas. By articulating this phrase with Foucault's concept of regimes of truth, we problematize links to narrow truths that naturalize hierarchical practices in the production of ways of being / feeling as teacher of mathematics, pointing out the importance of an exercise of freedom and otherness in our everyday practices in the classroom.
\end{abstract}

Keywords: teaching, mathematics teacher, freedom, regimes of truth, Foucault. 


\section{INTRODUÇÃO}

Estamos imbricados em respostas prontas, respostas fáceis. Automatismos estão presentes em nosso dia a dia com mais regularidade do que aquilo que nos causa estranheza. Esse "fazer sem pensar" é intenso, porque arraigado e costumeiro, mas é menos potente - e consideramos aqui a potência como uma mobilização de criação, uma vontade de movimento - do que aquilo que nos impulsiona e incita a pensar.

Automatismos são importantes pela praticidade que trazem às situações que nos tomam cotidianamente horas de nossos dias e que são necessárias, não podendo ser ignoradas. Não é o objetivo desse escrito, assim, requerer a toda a situação um status de diferenciação, compreendida aqui como uma produção de algo que se diferencia, uma criação.

A discussão que propomos refere-se àquilo que não se discute mais, sobre o qual não se pensa mais, mas que ainda carrega uma potência de ser pensado e vivido de outros modos; àquilo que se naturalizou em meio às inúmeras possibilidades ainda não experienciadas, porque uma ordem vigente, por meio de práticas específicas, valora saberes, fazeres, sentires e determina verdades.

É nesse contexto que se problematiza não a repetição do mesmo ou os automatismos, mas sua imposição como única possibilidade, como verdade absoluta e natural, em detrimento de modos outros de existência, modos onde a contingência e finitude não figurem como obstáculos ao ser, mas sim como condições de possibilidade. O foco desse escrito é, então, apresentar uma aproximação possível entre estudos de Foucault, ou parte de seus estudos, e a docência em Educação Matemática, ao fazer um exercício que busca instigar outros modos de pensar esta docência.

\section{Desnaturalizando o enunciado "isto não é matemática"}

Foucault mostra, através da exposição de distintos dispositivos, como se dá a experiência de ser sujeito através de tecnologias de subjetivação. Essas tecnologias permitem a vinculação do sujeito consigo mesmo, através de práticas específicas, sob o regimento de determinadas verdades. A constituição de modos de existência se dá através de jogos enunciativos, que produzem posições de sujeitos na malha discursiva. O sujeito estabelece para si o verdadeiro e o falso, imerso em uma política, em um sistema que pontua hierarquicamente o que é válido ou não ser pensado, dito e praticado. 
A verdade é tomada como o espaço institucional de legitimidade do discurso, a condição de proferir um logos - o discurso, em imanência, produz e reproduz verdades. Considerando esses regimes de verdade em seu caráter histórico, localizado e datado e, portanto, em sua condição mutável ou transformável, encontram-se, através do estudo dos escritos de Foucault, condições para tensionar a lógica que impera ao se naturalizar o discurso científico matemático, aquele tomado como eterno, indubitável e único - indiscriminadamente em nossas salas de aula, pois a manutenção de uma verdade única impede a elaboração de novos modos de ser, modos de fazer, de sentir, de estar no mundo. "O fechamento é a morte" (VEIGA-NETO, 2004, p. 62).

Cabe-nos então, enquanto educadores, a tarefa de discutir os fazeres e saberes esperados nas aulas de matemática, questionar os regimes de verdade que são produzidos acerca do conhecimento desta disciplina, entre automatismos operacionais e lógicos, entre expectativas de repetição e modelação. Segundo Veiga-Neto, “as verdades são inseparáveis das políticas que as instituíram" (2004, p. 45) e, nesse contexto, precisam ser problematizadas constantemente.

Na sala de aula, deparamo-nos com situações que exigem uma técnica proveniente da repetição e que geram conhecimentos e práticas úteis, das quais, com o tempo, lançamos mão sem muito esforço. Quando saímos desse espaço protocolar, podemos perceber o desconforto produzido. Citamos um exemplo: por vezes, pedimos aos alunos que expliquem, oralmente ou por escrito, o que é multiplicar (ou qualquer outra operação, forma geométrica etc.) em detrimento de sua efetuação. Ao se depararem com a reformulação do problema considerando que desde o domínio da técnica de multiplicação é comum apenas realizar a operação -, eles reagem, dizendo: "Isto não é matemática". Este enunciado é repetido por nossos alunos, incontáveis vezes, em atividades diversas que lhes são propostas, principalmente quando estas envolvem leitura ou a construção de um argumento.

"Isto não é matemática" se articula a outros enunciados, na produção de um princípio restritivo, limitador, do fazer nas aulas de matemática. O que faz sentido, o que pode ser dito, o que é válido fazer nas aulas de matemática? Que práticas, discursos, documentos, constroem esses limites e possibilitam que alunos, recém egressos dos anos iniciais do Ensino Fundamental, estabeleçam conexões que permitem dizer o que é e o que não é matemática? Por que acontece esta resistência por parte dos estudantes quando se deparam com leitura, escrita, história, na disciplina de matemática? 
Discussões como essas podem ser pensadas a partir do conceito - regimes de verdade - de Foucault. Um regime de verdade compõe-se de séries discursivas, que por sua vez são constituídas por enunciados que se sobrepõem e se relacionam dentro de um campo que institui o que é possível ser dito, o que é válido ser proferido, o que faz sentido; estabelece, portanto, os limites do pensável. Judith Revel, estudiosa de Foucault, argumenta que "cada sociedade possui seu regime próprio de verdade” (REVEL, 2005, p. 86), isto é:

Os tipos de discurso que elas acolhem e fazem funcionar como verdadeiros;
os mecanismos e as instâncias que permitem distinguir os enunciados
verdadeiros ou falsos, a maneira como uns e outros são sancionados; as
técnicas e os procedimentos que são valorizados para a obtenção da verdade;
o estatuto daqueles que têm o poder de dizer aquilo que funciona como
verdadeiro. (FOUCAULT apud REVEL, 2005, p. 86).

Problematizar os regimes de verdade da Educação Matemática nos permite desnaturalizar práticas, estabelecer novas vinculações, balançar os muros indubitáveis da verdade que carregam a matemática a um estado generalista e estático. É por que nenhum saber é politicamente neutro, que precisamos estar atentos e dispostos a esquadrinhar verdades, a fim de nos conduzirmos eticamente uns em relação aos outros. Pois, como asseveram Veiga-Neto e Lopes (2010, p. 162), tentar "pensar de outro modo" é o que "nos dará clareza e munição para lutarmos contra os mecanismos que nos parecem menos desejáveis para um mundo mais justo e igualitário".

Trata-se então de "ver historicamente como se produzem efeitos de verdade no interior de discursos que não são em si nem verdadeiros nem falsos” (FOUCAULT, 2015, p. 44), visto que se estabelecem em meio a relações que os localizam em um determinado hemisfério dessa dualidade, de maneira contingencial e transitória. Dualidade essa que não é dada a priori, mas que também se constitui por meio de práticas discursivas específicas.

Os enunciados que se emaranham acerca do que é ou não é matemática, ou ainda do que pertence ou não pertence à disciplina de matemática, resultam de políticas curriculares específicas e direcionantes, como livros didáticos, cursos de formação de professores, materiais utilizados, que determinam quais conhecimentos são válidos e que posicionam discursos em meio a jogos do verdadeiro e do falso.

A escrita, a história e outras experiências não ocupam a mesma posição no sistema de valoração científico. Um cálculo arbitrário ou o raciocínio algébrico abstrato definem, hoje, o lugar ocupado pela disciplina matemática, relegando a leitura, a dúvida e a argumentação a um status inferior. Essas observações não visam sobrepor saberes ou defender a realização de 
uma prática excludente sobre os fazeres nas aulas de matemática. Mas, antes, de problematizar a produção de um corpus de conhecimento bastante homogêneo, que fixa significados, (re)produz representações e prescreve condutas e saberes.

Propomos, então, a abertura de espaços na aula de matemática para o surgimento de perguntas que não estão prescritas, para a mobilização de estratégias outras que, ainda que não se possa generalizá-las, colocam o problema matemático em movimento promovendo novos olhares sobre ele. Com isso não queremos dizer que a aula de matemática é um valetudo, que trabalhar com os alunos erros e equívocos na resolução de um problema é traumatizá-lo e, portanto, se deve abrir mão do exame, da correção e dos direcionamentos. O objetivo é repensar nosso papel enquanto docentes, é tentar repensar esses binarismos que por vezes nos regem, é perceber que não há um manual de condutas certas e erradas aplicáveis em qualquer contexto e para todo e qualquer professor. Adotar esta postura implica um exercício constante de desconfiar de si mesmo, de sua prática; trata-se de aceitar que nunca estamos prontos, que somos limitados, finitos e que, por isso, vemos em parte. É nesse sentido que consideramos que o exercício da docência sempre passa por uma prática de liberdade e alteridade.

Se trazemos liberdade e alteridade na mesma frase é porque percebemos ambas as práticas como imbricadas uma na outra. O ser humano como ser relacional tem sua liberdade mediada pela liberdade do outro. A esse respeito, Bauman (1998, p. 40, grifo do autor), sociólogo polonês, argumenta:

A liberdade é uma relação - uma relação de poder. Sou livre, se, e somente
se posso agir de acordo com minha vontade e alcançar os resultados que
pretendo alcançar; isso significa, porém, que algumas outras pessoas serão
inevitavelmente restringidas em suas escolhas pelos atos que eu executei, e
que elas deixarão de alcançar os resultados que elas desejavam. De fato, eu
não posso medir a minha própria liberdade em termos absolutos - só posso
medi-la relativamente, comparando-a com a capacidade de outra pessoa de
consegui-la a seu modo.

Porém, essa percepção relacional da liberdade é solapada pela captura da palavra liberdade pelo mercado. Em tempos líquidos, para usar a metáfora baumaniana, a liberdade é ressignificada como liberdade de escolha, como liberdade individual, como liberdade de consumo. Ser livre é ser livre do outro. Na lógica neoliberal orientada para a competição o outro é sempre um concorrente. O valor do outro, assim como o valor de todas as coisas, passa a ser balizado em função de sua utilidade mercadológica. Responsabilidade agora tem a 
ver com o próprio self, significa "do começo ao fim, responsabilidade para consigo mesmo" (BAUMAN, 2011, p. 59, grifo do autor). Assim, quando o único responsável pela miséria humana passa a ser o próprio indivíduo, o vínculo social desse com os demais é fragilizado, levando a um esvaziamento das relações humanas, ao mesmo tempo em que há uma desresponsabilização do Estado e, consequentemente, uma privatização da vida.

Essa mercadologização da vida se explicita também no modo como nos relacionamos com a Educação. Os saberes são esvaziados de seus conteúdos, passando a se constituir de habilidades e competências. Habilidades e competências requeridas no mercado de trabalho, tendo pouca importância o que se pode chamar de patrimônio cultural da humanidade. Se uma leitura informa, ensina algo que tem aplicação imediata no contexto social, terá seu valor legitimado. Ao contrário, se for muito extensa, se não se puder capturar sua utilidade para uma prova de vestibular ou para uma entrevista de emprego, será extirpada da sala de aula. Como exemplo citamos o pouco espaço (ou nenhum) que há nos livros didáticos de matemática para o estudo de autores como Lewis Carroll, Malba Tahan, Monteiro Lobato, dentre outros. Autores que possibilitariam o estudo da matemática para além do seu caráter instrumental, mas que acabam não sendo veiculados pelo discurso pedagógico neoliberal. Talvez essa ausência do literário nos livros didáticos de matemática nos diga alguma coisa sobre o "Isto não é matemática" dos alunos, enunciado que pertence a um regime de verdade que faz muito mais do que estabelecer os limites entre um saber e outro.

No sentido de tensionar o valor meramente econômico que é atribuído ao conhecimento, de problematizar o conceito de utilidade nos tempos em que vivemos, Nuccio Ordine (2016, p. 9, grifo do autor), professor de literatura da Universidade de Calábria, apresenta que

Há saberes que têm um fim em si mesmos e que - exatamente graças à sua natureza gratuita e livre de interesses, distante de qualquer vínculo prático e comercial - podem desempenhar um papel fundamental no cultivo do espírito e no crescimento civil e cultural da humanidade. Nesse sentido, considero útil tudo o que nos ajuda a nos tornarmos melhores.

Embora se possa questionar essa expressão "livre de interesses" associada a determinados saberes, essa citação nos ajuda a pensar naquilo que se entende por útil, oferecendo uma outra chave para pensar esse conceito, muito mais abrangente porque considera a humanidade, a cultura, o social, e não apenas o indivíduo isolado, detentor e senhor do conhecimento. Nascemos inseridos num espaço-tempo históricos, numa dada 
cultura e orientamo-nos, constituímo-nos, segundo códigos, símbolos, narrativas, que muitas vezes nos escapam. Herdamos um patrimônio histórico e cultural que não pode ser ignorado, desprezado em prol de interesses de mercado, pois, uma vez que não somos indivíduos sem passado, uma vez que a humanidade não nasceu quando nascemos, mas já estava aí, existe algo a aprender com esse passado. A maneira como contamos o passado veicula o modo como contamos a nós mesmos no tempo, modulando nossas condutas e formas de vida.

Assim, o silêncio dos livros didáticos, das propagandas de televisão e de outros artefatos da mídia a respeito do fundamental caráter não utilitário do conhecimento, de suas intrínsecas conexões com outros campos e com outras esferas da vida, reforça ainda mais a necessidade de uma escola muito mais atenta a seu papel ético, que se estabelece num horizonte de tensionamentos e disputas de poder, do que à finalidade de tão somente fornecer mão de obra qualificada.

Ao professor de matemática cabe, então, o não-silenciar. Desfamiliarizar as falas dos alunos, estranhá-las. As suas também. Desnaturalizar as enunciações que ouvimos, as palavras que utilizamos, porque

Não há crítica da política existente nem possibilidade de invenção de uma política outra que não passe (também) pela crítica da linguagem política existente e pela invenção de uma linguagem política outra. Não há revolta política que não passe pela revolta linguística (LARROSA, 2004, p. 247).

Trata-se de perceber então que o conhecimento não é apenas expresso, comunicado, transmitido pela linguagem, mas constitui-se pela e na linguagem. Portanto, o modo de ensinar um determinado conteúdo já vincula ele próprio um conteúdo que vai muito além do que se pensa ensinar. Não são o pensamento ou o conhecimento instâncias dadas a priori, independente da linguagem, mas são as palavras que nos ensinam o nosso próprio pensamento (MERLEAU-PONTY apud DERRIDA, 2014, p. 14).

\section{Considerações finais}

Através dos estudos de Foucault, considerando especialmente a Educação Matemática, pensamos que é possível propor a produção de relações menos estreitas, efetuar deslocamentos no interior dos jogos de linguagem já naturalizados no discurso pedagógico, ao refletirmos que não existe uma hierarquização entre saberes que não seja estabelecida historicamente, fortalecida e legitimada por mecanismos de regulação eficientes. 
"Isto não é matemática" e outros enunciados que a ele se relacionam delimitam um discurso acerca do que é matemática que direciona ações, constrói limites de conduta, radicaliza modos de pensar em sala de aula. Trata-se de uma produção de comportamentos, de modo que, por vezes, os sujeitos envolvidos simplificam, sem perceber, a complexidade das relações envolvidas e, talvez por isso, acabem por aceitar as regras do jogo como únicas e invioláveis. Não é possível fugir de seu estruturante, mas apostamos que é possível fazer vazar a estrutura e estabelecer novas vinculações nas fronteiras.

\section{REFERÊNCIAS}

BAUMAN, Zygmunt. O mal-estar da pós-modernidade. Tradução Mauro Gama, Cláudia Martinelli Gama. Rio de Janeiro: Zahar, 1998. 272 p.

. A ética é possível num mundo de consumidores?. Tradução Alexandre Werneck. Rio de Janeiro: Zahar, 2011. 272 p.

DERRIDA, Jacques. A escritura e a diferença. Tradução Maria Beatriz M. N. da Silva, Pedro Leite Lopes, Pérola de Carvalho. São Paulo: Perspectiva, 2014. 436 p.

FOUCAULT, Michel. Microfísica do Poder. Organização, introdução e revisão técnica de Roberto Machado. Rio de Janeiro: Paz e Terra, 2015. 431 p.

LARROSA, Jorge. Linguagem e Educação depois de Babel. Belo Horizonte: Autêntica, 2004.

ORDINE, Nuccio. A utilidade do inútil: um manifesto. Tradução Luiz Carlos Bombassaro. Rio de Janeiro: Zahar, 2016.

REVEL, Judith. Michel Foucault: conceitos essenciais. Tradução Maria do Rosário Gregolin, Nilton Milanez, Carlos Piovesani. São Carlos, SP: Claraluz, 2005. 96 p.

VEIGA-NETO, Alfredo. Michel Foucault e os Estudos Culturais. In: COSTA, Marisa (org.). Estudos Culturais em Educação. Porto Alegre: Editora da UFRGS, 2004. 244 p.

VEIGA-NETO, Alfredo; LOPES, Maura. Para pensar de outros modos a modernidade pedagógica. Educação Temática Digital. Uberlândia, v. 12, n. 1, p. 147-166, Jul/Dez 2010. 